\title{
CARACTERIZAÇÃO DA BIOMASSA DA BANANA-MAÇÃ (Musa spp.) EM DIFERENTES ESTÁDIOS DE MATURAÇÃO IN NATURA E DESIDRATADA
}

Kamilla Cescon da Silva ${ }^{1}$, Thamires Santos Neris ${ }^{2}$, Raquel Aparecida Loss ${ }^{3}$, Sumária Sousa e Silva ${ }^{4}$, Sumaya Ferreira Guedes ${ }^{5}$

1, 2 Graduada em Engenharia de Alimentos,Universidade do Estado de Mato Grosso

(UNEMAT), Barra do Bugres- MT, Brasil.

${ }^{3}$ Profa. Dra, Faculdade de Arquitetura e Engenharia, Universidade do Estado de Mato Grosso (UNEMAT), Barra do Bugres- MT, Brasil.

${ }^{4}$ Profa. Dra, Faculdade de Ciências Exatas e Tecnológica, Universidade do Estado de Mato Grosso (UNEMAT), Barra do Bugres- MT, Brasil.

${ }^{5}$ Profa. Dra, Faculdade de Arquitetura e Engenharia, Universidade do Estado de Mato Grosso (UNEMAT), Barra do Bugres- MT, Brasil.

(sumayaguedes@unemat.br)

Recebido em: 02/10/2017 - Aprovado em: 21/11/2017 - Publicado em: 05/12/2017 DOI: 10.18677/EnciBio_2017B12

O Brasil é considerado um país rico na produção e comercialização frutífera, tendo como consequência altas perdas pós colheita. $O$ reaproveitamento proveniente das frutas como a banana pode chegar até $60 \%$, sendo assim uma forma de agregar nutrientes a dieta como também tornar possível a elaboração de novos produtos com qualidades nutricionais. Uma maneira de minimizar a perda causada durante a colheita, transporte e armazenamento da banana é a produção de sua biomassa, sendo esta aplicada como matéria prima na elaboração de produtos funcionais. Diante disto, a presente pesquisa se propôs avaliar as características físico-químicas da biomassa da fruta in natura e desidratada, em diferentes estádios de maturação. As bananas foram separadas em função do grau de maturação desejado (verde, maduro e senescência). Parte da biomassa foi seca em estufa com circulação de ar forçado à $60^{\circ} \mathrm{C}$ para a obtenção da amostra desidratada, sendo realizadas modelagens das curvas de secagem para representação dos dados experimentais. O modelo de Page foi o que melhor representou os três estádios de maturação. Os resultados mostraram que a biomassa apresenta baixos teores de lipídios e cinzas nos três estádios de maturação, porém, quando verde apresentou alto teor de amido. No estádio maduro, a biomassa apresentou elevados teores de açucares e acidez. Desta forma, conforme o amadurecimento da banana, as características físico-químicas sofreram modificações tanto na biomassa úmida quanto na desidratada. Porém, a desidratada apresentou maior valor nutricional em relação a in natura, devido ao menor teor de água.

PALAVRAS-CHAVE: Alimento Funcional; Cinética de Secagem; Modelagem Matemática 


\title{
CHARACTERIZATION OF THE BIOMASS OF BANANA-MAÇÃ (Musa spp.) IN DIFFERENT STAGES OF MATURATION IN NATURA AND DEHYDRATED
}

\begin{abstract}
Brazil is considered a rich country in fruitful production and commercialization, resulting in high post harvest losses. The reuse of fruits such as bananas can reach up to $60 \%$, thus being a way of adding nutrients to the diet as well as making possible the elaboration of new products with nutritional qualities. One way to minimize the loss caused during a harvest, transport and storage of the banana, is production of its biomass, being applied as raw material in the preparation of functional products. Therefore, the present research aimed to evaluate the physico chemical characteristics of the biomass of the fruit in natura and dehydrated, in different stages of maturation. The bananas were separated according to the degree of maturation desired (green, ripe and senescence). Part of the biomass was dried in an oven with forced air circulation at $60^{\circ} \mathrm{C}$ to obtain the dehydrated sample, and the drying curves were designed to represent the experimental data. The Page model was the one that best represented the three stages of maturation. The results showed that biomass presents low levels of lipids and ashes in the three stages of maturation, but when green showed high starch content. At the mature stage, biomass presented high levels of sugars and acidity.Thus, as banana ripening, the physicochemical characteristics have been changed both in wet and in dehydrated biomass. However, the dehydrated had higher nutritional value in relation to in natura, due to the lower water content.
\end{abstract}

KEYWORDS: Functional Food; Kinetics of Drying; Mathematical Modeling.

\section{INTRODUÇÃO}

Considerada uma das frutas mais consumidas no mundo, a banana é explorada nos países tropicais, sendo cultivada em todos os estados do Brasil, ocupando o segundo lugar entre as frutas mais apreciadas pelos brasileiros. $O$ alto valor nutritivo e custo relativamente baixo fazem dela parte constituinte da alimentação da população brasileira (SILVA; RAMOS, 2009). Além disso é uma fruta com alto valor energético, chegando a aproximadamente $100 \mathrm{kcal}$ por $100 \mathrm{~g}$ de polpa, possuindo em torno de $22 \%$ de carboidratos, vitamina $\mathrm{C}$, traços de vitamina A, B1, B2, D e E, além de superar os valores de potássio, fósforo, cálcio e ferro de outras frutas (FASOLIN et al., 2007).

O Brasil é considerado atualmente o quinto maior produtor mundial de banana, destacando a região Nordeste como maior produtor (OLIVEIRA et al., 2016). No Brasil, o índice de perdas na comercialização da banana faz com que apenas $60 \%$ da produção chegue à mesa do consumidor. $O$ aproveitamento destas perdas pode contribuir para melhorar a qualidade nutricional do cardápio, reduzir o desperdício de alimentos e também tornar possível a elaboração de novos produtos com qualidade nutricional (GONDIM et al., 2005).

Assim, a industrialização pode ser uma opção no aproveitamento de sobras de produção de frutos que não estejam dentro do padrão para o consumo in natura (SILVA; RAMOS, 2009). Devido à crescente preocupação com a alimentação saudável, a biomassa de banana apresenta-se como uma opção na produção de alimentos funcionais devido ao elevado teor de fibras (ALENCAR et al., 2014).

Diante da importância da cultura da banana no Brasil e a falta de dados no acompanhamento do amadurecimento dessa fruta, esta pesquisa propôs avaliar as 
características físico-químicas da biomassa de banana maçã (in natura) e desidratada.

\section{Obtenção da matéria-prima}

\section{MATERIAL E MÉTODOS}

As bananas da espécie maçã foram cultivadas no Assentamento Antônio Conselheiro e adquiridas em feira livre no município de Barra do Bugres, MT. Para o preparo da biomassa, as frutas foram obtidas no estádio de maturação verde, e posteriormente armazenadas até atingir o estádio de maturação desejado para a produção das demais biomassas (madura e senescência), como mostra a Figura 1.

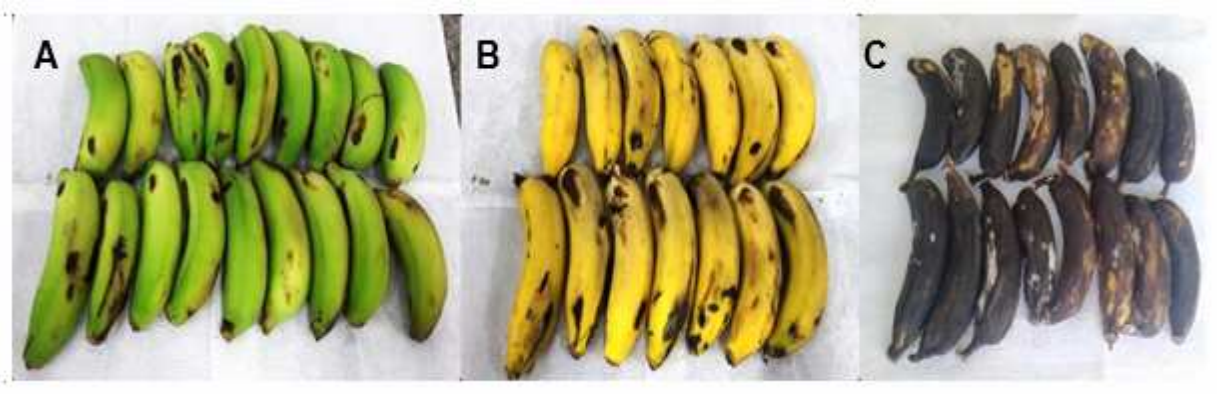

FIGURA 1. Estádios de Maturação da Banana Maça. A) Verde; B) Madura; C) Senescência.

FONTE: Autoria própria (2017).

O preparo das biomassas foi realizado no Laboratório de Processamento e Tecnologia de Alimentos e as análises físico-químicas no Laboratório de Química Experimental, ambos pertencentes à Universidade do Estado de Mato Grosso, Campus Deputado Estadual Renê Barbour. As análises de proteínas foram realizadas no Laboratório de Nutrição Animal da Universidade Federal do Mato Grosso, Campus Rondonópolis, MT.

\section{Preparo da Biomassa}

Para a produção da biomassa selecionou-se as bananas em relação ao estádio de maturação (verde, maduro e senescência). Após seleção, as bananas foram higienizadas e submetidas ao processo de cocção em panela de pressão doméstica por 20 minutos e, posteriormente, trituradas em liquidificador doméstico até a obtenção de uma massa pastosa (Figura 2).

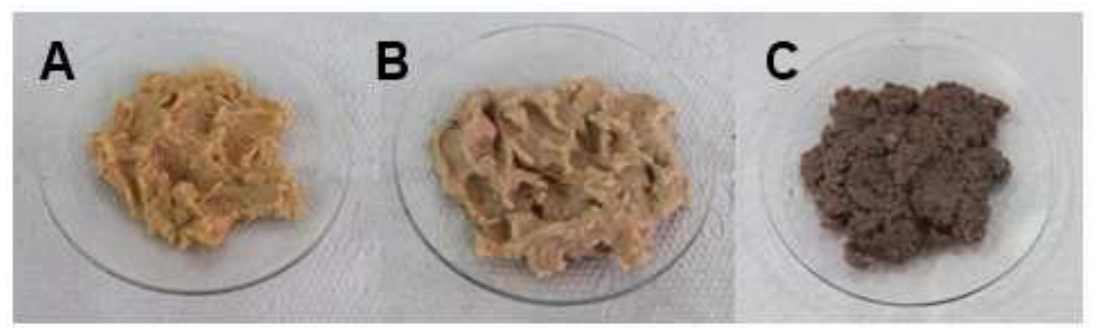

FIGURA 2. Biomassa Úmida. A) Verde; B) Madura; C) Senescência. FONTE: Autoria própria (2017). 
Posteriormente, parte da biomassa foi submetida a secagem em estufa com circulação forçada de ar a $60^{\circ} \mathrm{C}$. A biomassa desidratada foi triturada em cadinho de porcelana com pistilo (Figura 3), armazenada em frascos âmbar e refrigeradas a $4^{\circ} \mathrm{C}$ até o momento das análises físico-químicas.

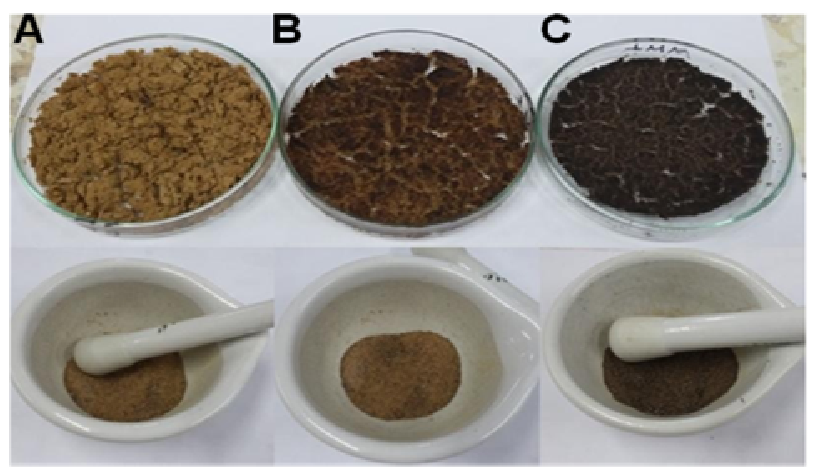

FIGURA 3. Biomassa Desidratada. A)

Verde; B) Madura; C) Senescência

FONTE: Autoria própria (2017).

\section{Cinética de secagem}

$\mathrm{Na}$ secagem das biomassas foram realizadas pesagens periódicas, até massa constante. A razão de umidade (RU) foi estabelecida conforme a Equação 1.

$$
R U=\frac{\left(U-U_{e}\right)}{\left(U_{i}-U_{e}\right)} \quad \text { Equação } 1
$$

Onde: $U=$ teor de água do produto, decimal b.s; $U i=$ teor de água inicial do produto, decimal b.s; Ue= teor de água de equilíbrio do produto, decimal b.s.

Para a representação das curvas de secagem, utilizaram-se três modelos matemáticos amplamente utilizados para a representação de curvas de secagem de produtos agrícolas (Page, Henderson e Pabis e Midili e Kucuk).. A escolha do modelo que melhor se ajustou aos dados experimentais foi realizada em função da correlação e do erro padrão médio.

\section{Análises físico-químicas da biomassa úmida e desidratada}

As biomassas úmidas e desidratadas foram submetidas às análises físicoquímicas de umidade, acidez titulável, $\mathrm{pH}$, cinzas, lipídios e amido e as análises de açúcares totais foram realizadas de acordo com Instituto Adolfo Lutz (2008) e Maldonade et al. (2013). Todas as análises foram realizadas em um mínimo de triplicatas.

\section{Análise estatística}

A análise estatística foi realizada com a utilização do software Assistat 7.7., por comparação entre médias pelo teste de Tukey, com nível de significância a $5 \%$ $(p<0,05)$. 


\section{RESULTADOS E DISCUSSÕES}

\section{Cinética de Secagem}

A Figura 4 apresenta o comportamento das curvas de secagem das biomassas de banana verde, madura e em estado de senescência, na temperatura de $60^{\circ} \mathrm{C}$.

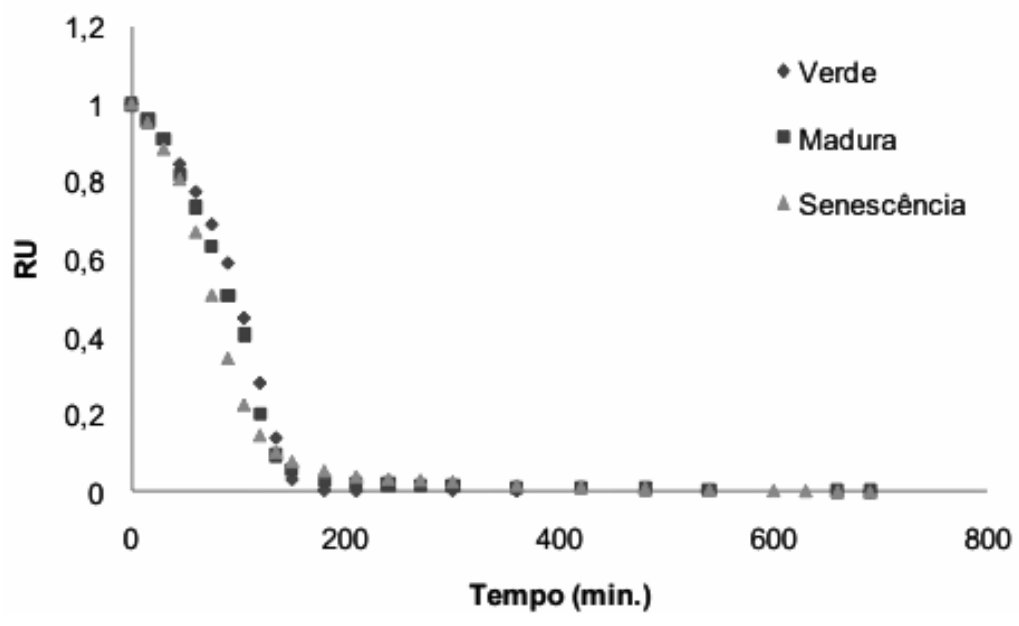

FIGURA 4. Curvas de secagem das biomassas de banana maçã a $60^{\circ} \mathrm{C}$.

FONTE: Autoria própria (2017).

Através desses dados foi possível verificar que a secagem apresentou-se semelhante para as três biomassas analisadas, no entanto, a biomassa em estado verde atingiu o equilíbrio mais rápido, levando aproximadamente 200 minutos (três horas e 20 minutos), enquanto que a madura e a em estado de senescência levaram aproximadamente 300 minutos (cinco horas) para atingir o equilíbrio. Essa diferença pode ser explicada pelo fato da biomassa em estado verde possuir menor umidade em comparação à madura e a em estado de senescência, necessitando assim de menor tempo de secagem.

O tempo de secagem encontrado no presente estudo para as três biomassas avaliadas foi inferior ao tempo obtido por Leite et al. (2015), para a secagem de banana variedade Terra, que obtiveram um tempo de 780 minutos na temperatura de $50^{\circ} \mathrm{C}$.

Estas curvas de secagem foram representadas por modelos matemáticos, cujos resultados são apresentados na Tabela 1 que mostra os parâmetros dos modelos ajustados aos dados experimentais da secagem das biomassas de banana maçã, bem como a correlação e erro padrão médio de cada ajuste. 
TABELA 1. Parâmetros dos modelos matemáticos ajustados para a cinética de secagem das biomassas de banana maçã.

\begin{tabular}{ccccc}
\hline Modelos & Parâmetros & Verde & Madura & Senescência \\
\hline \multirow{2}{*}{ Henderson } & $\mathrm{a}$ & 1,298141 & 1,305397 & 1,175366 \\
e Pabis & $\mathrm{k}$ & 0,011987 & 0,012058 & 0,014111 \\
& $\mathrm{r}$ & 0,957918 & 0,967342 & 0,974442 \\
& Erro & 8,158703 & 7,995689 & 6,664101 \\
\hline \multirow{2}{*}{ Midilli e } & $\mathrm{a}$ & 1,000000 & 0,998982 & 0,952932 \\
Kucuk & $\mathrm{b}$ & 0,000001 & 0,000000 & 0,000010 \\
& $\mathrm{k}$ & 0,000100 & 0,000004 & 0,000008 \\
& $\mathrm{n}$ & 2,000000 & 2,698278 & 2,611722 \\
& $\mathrm{r}$ & 0,988969 & 0,997423 & 0,998196 \\
Page & Erro & 55,483011 & 55,18688 & 55,19268 \\
& $\mathrm{k}$ & 0,000011 & 0,000004 & 0,000011 \\
& $\mathrm{n}$ & 2,500000 & 2,700000 & 2,544241 \\
& $\mathrm{r}$ & 0,987898 & 0,997383 & 0,998523 \\
& Erro & 0,797143 & 0,461346 & 0,526204
\end{tabular}

FONTE: Autoria própria (2017).

Na modelagem da biomassa de banana observou-se que independentemente do estádio de maturação, os maiores valores de correlação foram obtidos para os modelos de Midilli e Kucuk e de Page, sendo este valor muito próximo entre os dois modelos. No entanto, o modelo de Page apresentou o menor erro padrão médio, em relação aos demais modelos utilizados. Além disso, outro fator importante que deve ser levado em consideração na escolha de um modelo matemático é a parcimônia, que diz que quando dois modelos se ajustam igualmente, o que necessitar de um menor número de parâmetros será o escolhido. No caso dos modelos aplicados, o Midilli e Kucuk apresentam quatro parâmetros, enquanto que o modelo de Page possui apenas dois parâmetros. Assim, o modelo de Page é o que melhor se ajustou aos dados experimentais de secagem das biomassas de banana, nos três estádios de maturação.

O modelo de Page também foi o que melhor representou a secagem convectiva da banana nanica no estudo de Gonçalves et al. (2016), sendo que os autores obtiveram uma correlação maior que 0,9. Dandamrongrak et al. (2003) também obtiveram uma correlação acima de 0,90 para o modelo da Page na secagem de banana a $50^{\circ} \mathrm{C}$. Trabalhos envolvendo a secagem de diferentes frutos também relataram que o modelo de Page foi o que melhor se ajustou aos dados experimentais, como é o caso de Machado et al. (2012) na secagem de abacaxi pérola.

O ajuste dos modelos aos dados experimentais também pode ser observado na Figura 5 onde estão apresentadas as curvas de secagem das biomassas de banana maçã nos três estádios de maturação, ajustadas pelos modelos de Henderson e Pabis, Midilli e Kucuk e o modelo de Page. 

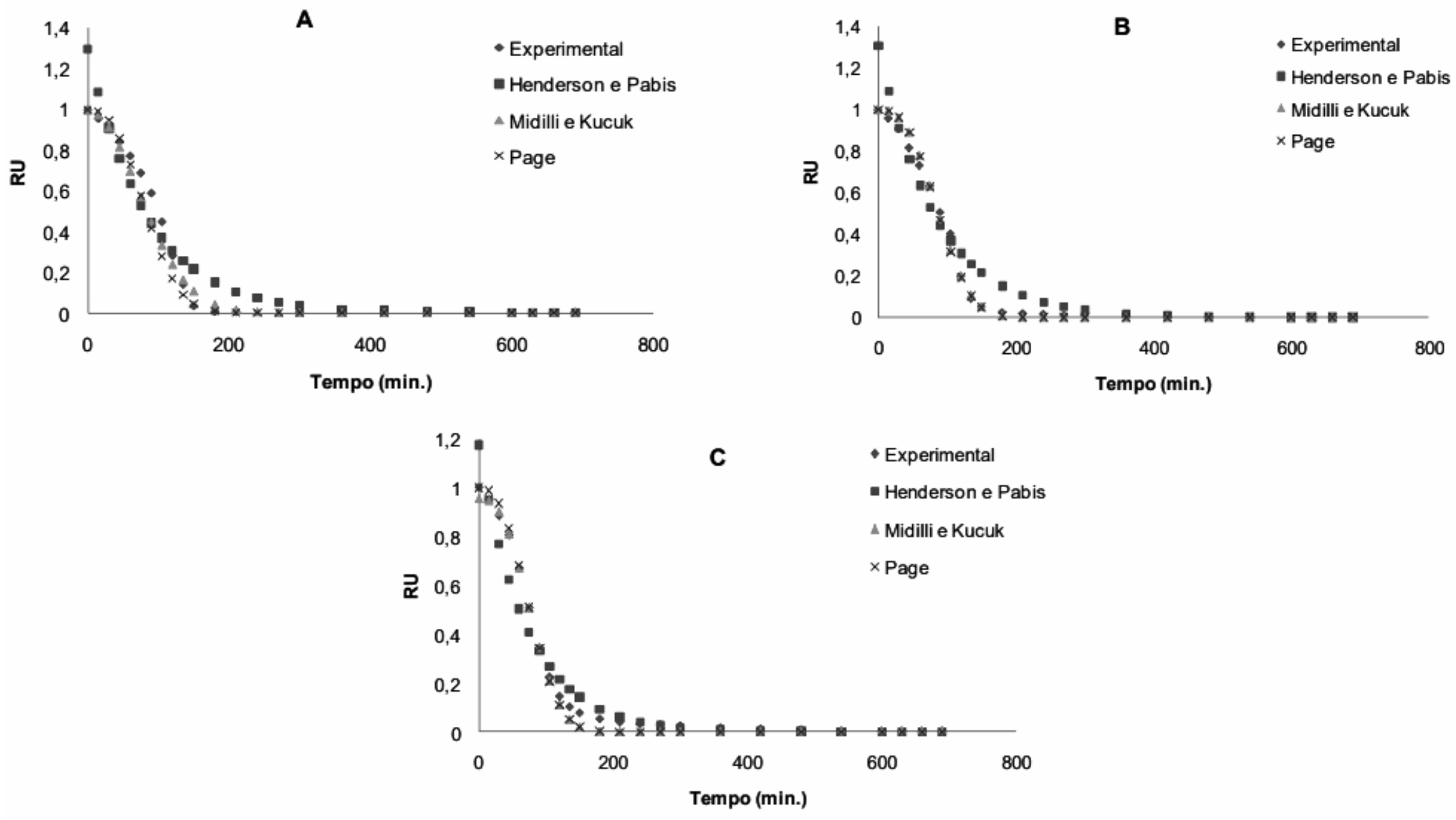

FIGURA 5. Curva de secagem da biomassa de banana. A)Verde; B)Madura; C)Senescência.

FONTE: Autoria própria (2017). 


\section{Análises físico-química da biomassa da banana maça}

Os resultados obtidos na caracterização físico-química da biomassa de banana maçã (verde, madura e em estado de senescência) úmida e desidratada, são apresentados através da média e desvio padrão na Tabela 2. A umidade presente nas biomassas de banana independente do estádio de maturação está relacionada com a água contida nos frutos e também à quantidade de água absorvida pelas bananas no processo de cocção. Foi observado aumento de umidade com o amadurecimento. Este aumento, provavelmente foi ocasionado pela troca de umidade entre o ambiente e a banana, ocasionados pela respiração no processo de maturação. Dinon et al. (2014) obtiveram um teor de umidade de 67,4 $\%$, para a biomassa de banana nanica verde, valor menor quando comparado ao do presente estudo para banana maçã $(74,61 \%)$.

As cinzas diminuíram com o amadurecimento das bananas, possuindo um maior teor para a banana verde e um menor teor para a banana em estado de senescência. Esses resultados estão de acordo com Prill et al. (2012) que explicam que durante o amadurecimento dos frutos, os sais minerais apresentam variações, possuindo teores maiores na banana verde quando em comparação com o fruto maduro. O teor de cinzas na biomassa de banana verde foi superior $(1,14 \%)$ ao encontrado por Dinon et al. (2014) para a biomassa de banana nanica verde e inferior ao obtido por Fasolin et al. (2007) 2,62 \% para a farinha de banana prata verde. Essas diferenças podem ser atribuídas as diferentes cultivares e também pelo estádio de maturação que o fruto foi colhido.

A acidez é considerada uma propriedade importante na avaliação do estado de conservação de um alimento (BATISTA et al., 2013). De modo geral, como podese observar a acidez da biomassa desidratada apresentou-se maior do que na biomassa in natura (úmida), pois com a redução de umidade, os compostos se encontram mais concentrados. Em ambos os casos, o teor de acidez sofreu um aumento logo no início da maturação, seguido de um decréscimo até atingir a senescência. Isso se deve, porque, o teor de ácidos orgânicos diminui com a maturação das frutas, ao ser usado como substrato no processo respiratório ou em sua transformação em açúcares. Além disso, no estádio de maturação verde, a banana caracteriza-se pela baixa acidez, que no decorrer do amadurecimento vai aumentando até alcançar um máximo, quando a casca estará totalmente amarelada, para então decrescer (PRILL et al., 2012). Nascimento Junior et al. (2008) ao estudarem a acidez das bananas prata e nanicão em amadurecimento também verificaram aumento da acidez logo no começo da maturação e depois um pequeno decréscimo.

Em relação ao $\mathrm{pH}$, observou-se que as biomassas das amostras in natura e desidratada sofreram um decréscimo no começo da maturação e depois um aumento, corroborando com a acidez no fruto em estágio de amadurecimento. Nascimento Junior et al. (2008) ao estudarem as bananas prata e nanicão verificaram que $\mathrm{opH}$ decrescia no decorrer da maturação, obtendo um valor inicial para a banana prata de 4,60 e final de 4,06. Após a análise da banana nanicão foi observado um valor inicial de 5,14 e final de 4,53, diminuindo o $\mathrm{pH}$. Nascimento Junior et al. (2008) relatam ainda que é esperado esse decréscimo do $\mathrm{pH}$, pois esta diminuição está associada ao acúmulo de açúcares e constituintes ácidos que ocorre durante o amadurecimento dos frutos.

Uma das transformações mais evidentes que ocorre durante 0 amadurecimento da banana é a conversão do amido em açúcares simples, podendo 
apresentar até $27 \%$ de amido na composição e decrescendo para menos de $2 \%$ quando o fruto estiver completamente maduro. Esse fato foi observado tanto para a biomassa in natura quanto desidratada, uma vez que o teor de amido apresentou redução com o amadurecimento da fruta, sendo o maior teor no fruto verde e o menor no fruto em estado de senescência.

Ao estudar a biomassa de banana nanica verde, Dinon et al. (2014) encontraram um valor de $22,2 \%$ de amido, valor menor que o encontrado no presente estudo. Francisco et al. (2014) em seus estudos com a banana prata e nanica verde, encontraram um teor de amido próximo ao do presente estudo de 27,4 $\%$ e 23,6 \%, respectivamente. Já ao analisarem os mesmos parâmetros com a banana madura, encontraram valor menor do que o presente estudo de 1,92 e 1,7\% para a banana prata e nanica, respectivamente.

Como o amido é convertido em açúcares durante o amadurecimento da fruta, o teor de açúcares totais aumenta, fato evidenciado nos resultados obtidos na presente pesquisa. Nascimento Junior et al. (2008) verificaram em seus estudos com a banana prata e nanicão que o teor de açúcares também aumenta durante o amadurecimento do fruto, obtendo valor inicial de 0,2 e 0,17\% e valor final de 20,11 e $17,19 \%$ para a banana prata e nanicão, respectivamente.

Quanto ao teor de proteínas, foi observado que a biomassa de banana maçã em estado de senescência apresentou maior teor, tanto in natura quanto desidratada. Já a biomassa desidratada apresentou maiores teores de proteínas, por seus compostos se encontrarem concentrados. Os resultados obtidos corroboram com a literatura pois Dinon et al. (2014) encontraram para a biomassa de banana nanica verde um teor de $1,33 \%$ de proteínas. Ao caracterizar a farinha de banana prata verde, Silva e Ramos (2009) obtiveram valor de 3,51 \% de proteínas.

A fração lipídica nas biomassas de banana maçã apresentou-se baixa, possuindo $0,05 \%$ na banana verde e madura e 0,06 \% na banana em estado de senescência. Verificou-se que com o amadurecimento da banana, houve um pequeno acréscimo no teor de lipídios das biomassas. Os resultados obtidos no presente estudo foram menores do que os encontrados nas literaturas.

Nos estudos realizados por Dinon et al. (2014) e Silva e Ramos (2009), foram encontrados um teor de lipídios de 0,16 e 0,73 \% na biomassa de banana nanica e na banana prata, respectivamente. 
TABELA 2. Análises físico-química da biomassa da banana maçã in natura e desidratada em diferentes estádios de maturação.

\begin{tabular}{|c|c|c|c|c|c|c|c|c|c|}
\hline Biomassa & Maturação & $\begin{array}{c}\text { Umidade } \\
(\%)\end{array}$ & $\begin{array}{c}\text { Cinzas } \\
(\%)\end{array}$ & $\mathrm{pH}$ & $\begin{array}{c}\text { Acidez } \\
(\%)\end{array}$ & $\begin{array}{l}\text { Açúcares } \\
\text { totais (\%) }\end{array}$ & $\begin{array}{c}\text { Amido } \\
(\%)\end{array}$ & $\begin{array}{c}\text { Proteínas } \\
(\%)\end{array}$ & $\begin{array}{c}\text { Lipídios } \\
(\%)\end{array}$ \\
\hline \multirow{3}{*}{ in natura } & Verde & $74,61 \pm 0,06^{c}$ & $1,14 \pm 0,14^{\underline{a}}$ & $5,49 \pm 0,01^{b}$ & $4,47 \pm 0,33^{\mathrm{a}}$ & $3,56 \pm 0,05^{c}$ & $27,98 \pm 1,14^{a}$ & $1,51 \pm 0,04^{b}$ & $0,05 \pm 0,02^{\mathrm{a}}$ \\
\hline & Madura & $82,01 \pm 0,18^{a}$ & $0,82 \pm 0,18^{a b}$ & $5,18 \pm 0,02^{c}$ & $5,25 \pm 0,03^{a}$ & $5,57 \pm 0,32^{a}$ & $8,99 \pm 0,59^{b}$ & $1,07 \pm 0,07^{c}$ & $0,05 \pm 0,02^{\mathrm{a}}$ \\
\hline & Senescência & $80,71 \pm 0,26^{b}$ & $0,76 \pm 0,07^{b}$ & $6,01 \pm 0,01^{a}$ & $2,27 \pm 0,29^{b}$ & $5,18 \pm 0,3^{b}$ & $5,14 \pm 0,25^{c}$ & $1,72 \pm 0,08^{a}$ & $0,06 \pm 0,02^{\mathrm{a}}$ \\
\hline \multirow{2}{*}{ Desidratada } & Verde & $5,35 \pm 0,07^{c}$ & $4,18 \pm 0,15^{\underline{a}}$ & $5,33 \pm 0,01^{b}$ & $17,25 \pm 1,11^{b}$ & $12,49 \pm 1,04^{\underline{a}}$ & $73,02 \pm 2,39^{a}$ & $4,46 \pm 0,14^{c}$ & - \\
\hline & Senescência & $15,74 \pm 1,92^{\mathrm{a}}$ & $4,24 \pm 0,11^{\text {a }}$ & $5,88 \pm 0,08^{a}$ & $18,63 \pm 1,09^{b}$ & $13,38 \pm 0,43^{a}$ & $22,7 \pm 2,11^{\mathrm{C}}$ & $5,92 \pm 0,19^{b}$ & - \\
\hline
\end{tabular}

Letras iguais na mesma coluna não diferem significativamente pelo teste de Tukey $(p<0,05)$, para cada uma das biomassas. 0 teste de comparação de média foi aplicado separadamente entre a biomassa de banana verde in natura e desidratada. FONTE: Autoria própria (2017). 


\section{CONCLUSÕES}

Diante dos resultados obtidos com a caracterização físico-química da biomassa da banana maçã in natura e desidratada em diferentes estádios de maturação, foi possível observar que a biomassa da banana maçã apresentou baixo teor de proteínas, lipídios e cinzas nos três estádios de maturação.

O grau de maturação da banana influencia diretamente no teor de acidez e $\mathrm{pH}$ do fruto, com diminuição da acidez e aumento do $\mathrm{pH}$. O teor de amido diminuiu consideravelmente com o amadurecimento da banana maça, aumentando o teor de açucares.

\section{AGRADECIMENTOS}

Os autores agradecem à Universidade do Estado de Mato Grosso (UNEMAT) e Fundação de Amparo à Pesquisa de Mato Grosso (FAPEMAT) pelo apoio financeiro e estrutural para realização desta pesquisa.

\section{REFERÊNCIAS}

ALENCAR, L. O.; SANTOS, E. D. S.; FERNANDES, A. C. C. F. Desenvolvimento, aceitabilidade e valor nutricional de brigadeiro com biomassa de banana verde. Revista Interdisciplinar, Vale do Araguaia, v.7, n.4, p. 91-98, 2014.

BATISTA, A. G.; OLIVEIRA, B.A.; OLIVEIRA, M.A.; GUEDES, T.J.; SILVA, D.F.; PINTO, N.A.V.D. Parâmetro de qualidade de polpas de frutas congeladas: uma abordagem para produção do agronegócio familiar no Alto Vale do Jequitinhonha. Tecnologia e Ciência Agropecuária, João Pessoa, v.7, n.4, p.49-54, dez. 2013.Disponível em: <http://revistatca.pb.gov.br/edicoes/volume-07-2013/volume-7numero-4-dezembro-2013/tca7409.pdf>

DANDAMRONGRAK, R.; MASON, R.; YOUNG, G. The effect of pretreatments on the drying rate and quality of dried bananas. International Journal Food Science and Technology, v. 38, p.877-882, 2003. Disponível em: < http://dx.doi.org/ 10.1046/j.0950-5423.2003.00753.x>. doi: 10.1046/j.0950-5423.2003.00753.x

DINON, S.; DEVITTE, S.; CANAN, C.; KALSCHNE, D. L.; COLLA, E. Mortadela tipo Bologna com reduzido teor de lipídios pela adição de biomassa de banana verde, pectina, carragena e farinha de linhaça. Revista Ciências Exatas e Naturais, Paraná, v.16, n.2, p. 229-246, 2014. Disponível em: <http://revistas.unicentro.br/index.php/RECEN/article/view/2949/2524>

FASOLIN, L. H.; ALMEIDA, G. C.; CASTANHO, P. S.; NeTO-OliVEIRA, E. R. Biscoitos produzidos com farinha de banana: avaliações química, física e sensorial. Ciência e Tecnologia de Alimentos, Campinas, v.27, n.3, p. 524-529, 2007.Disponível em: <http://www.scielo.br/pdf/cta/v27n3/a16v27n3.pdf>

GONÇALVES, J.Q.; SILVA, M. A. P.; PLÁCIDO, G. R.; CALIARI, M.; SILVA, R. M.; MOURA, L. C.; SOUZA, D. G. Secagem da casca e polpa da banana verde (Musa acuminata): propriedades físicas e funcionais da farinha. Global Science Technology, Rio Verde, v.09, n.03, p.62-72, 2016. Disponível em: $<$ https://rv.ifgoiano.edu.br/periodicos/index.php/gst/article/view/831/515> 
GONDIM, J. A. M.; MOURA, M. F. V.; DANTAS, A. S.; MEDEIROS, R. L. S.; SANTOS, K. M. Composição centesimal e de minerais em cascas de frutas. Ciência e Tecnologia de Alimentos, Campinas, v.25, n.4, p. 825-827, 2005. Disponível em: $<$ http://www.scielo.br/pdf/cta/v25n4/27658.pdf>

INSTITUTO ADOLFO LUTZ. Métodos físico-químicos para análise de alimentos. Edição IV, Brasília: Instituto Adolfo Lutz, 2008.

MACHADO, A. M.; SOUZA, M. C.; JUNQUEIRA, M. S.; Cinéticas de secagem do abacaxi cv. Pérola. Enciclopédia Biosfera, Centro Científico Conhecer, Goiânia, v.8, n.15, 2012. Disponível em: <http://www.conhecer.org.br/enciclop/2012b/ciencias\%20agrarias/cineticas\%20de\%2 Osecagem.pdf>

FRANCISCO, M. S.; ARAÚJO, R. C.; SANTOS, E. P.; GOMES, F. F. B.; CRUZ, G. R. B. Efeito das condições de manejo nas características sensoriais de banana (Musa spp.) cv. pacovan. Revista Brasileira de Fruticultura, Jaboticabal - SP, v. 36, n. 2, p. 313-317, 2014. Disponível em: <http://www.scielo.br/pdf/rbf/v36n2/v36n2a06.pdf>

LEITE, A.L.M.P.; SILVA, F.S.; PORTO, A.G.; PIASSON, D.; SANTOS, P. Contração volumétrica e cinética de secagem de fatias de banana variedade Terra. Pesquisa Agropecuária Tropical, Goiânia, v. 45, n. 2, p. 155-162, 2015. Disponível em: http://www.scielo.br/pdf/pat/v45n2/1517-6398-pat-45-02-0155.pdf.

MALDONADE, I. R.; CARVALHO, P. G. B. de; FE.RREIRA, N. A. Protocolo para determinação de açúcares totais em hortaliças pelo método de DNS.Brasília, DF: Embrapa Hortaliças, 2013.

NASCIMENTO JUNIOR, B. B.; OZORIO, L. P.; REZENDE, C. M.; SOARES, A. G.; FONSECA, M. J. O. Diferenças entre bananas de cultivares Prata e Nanicão ao longo do amadurecimento: características físico-químicas e compostos voláteis. Ciência e Tecnologia de Alimentos, Campinas, v.28, n.3, p.649-658, 2008. Disponível em: <http://dx.doi.org/10.1590/S0101-20612008000300022>

OLIVEIRA, C. R.; SANTOS, M. B.; SANTOS, M. F. G. O potencial funcional da biomassa de banana verde (Musa spp.) na simbiose intestinal. Revista Ciência e Sociedade, Macapá, n.1, v.1, 2016. Disponível em: <http://revistapuca.estacio.br/index.php/cienciaesociedade/article/view/2145/1225>

PRILL, M.A. de S.; NEVES, L.C.; CHAGAS, E.A.; TOSIN, J.M.; SILVA, S.S. Métodos para a climatização de bananas 'Prata-Anã' produzidas na Amazônia setentrional brasileira. Revista Brasileira de Fruticultura, v.34, p.1030-1042, 2012.

Disponível em: <http://dx.doi.org/10.1590/S0100-29452012000400009>. doi: 10.1590/ S0100-29452012000400009

SILVA, M. B. L.; RAMOS, A. M. Composição química, textura e aceitação sensorial de doces em massa elaborados com polpa de banana e banana integral. Revista 
Ceres, Viçosa, v.56, n.5, p. 551-554, 2009. Disponível em: <http://www.ceres.ufv.br/ojs/index.php/ceres/article/view/3465/1362> 